\title{
Merancang Media Pembelajaran Berbasis Web Menggunakan Aplikasi Dreamweaver Pada SMAN 1 Kapoiala
}

\author{
Yunita $^{1}$, Aris Susanto ${ }^{2}$ \\ ${ }^{1}$ Universitas Muhammadiyah Kendari \\ ${ }^{2}$ STMIK Bina Bangsa Kendari \\ arissusantoh@gmail.com
}

\begin{abstract}
Abstrak
Penelitian ini bertujuan merancang media pembelajaran berbasis web untuk mempermudah kegiatan belajar dan menyajikan materi yang interaktif agar dapat meningkatkan minat siswa/i dalam belajar mata pelajaran Ilmu Pengetahuan Alam di SMAN 1 Kapoiala. Aplikasi yang digunakan untuk merancang media pembelajaran adalah dreamweaver dan selanjutnya dilakukan uji kelayakan oleh ahli media sebanyak 2 orang, ahli materi sebanyak 2 orang serta uji coba dilakukan kepada siswa sebanyak 20 orang. Hasil uji kelayakan berdasarkan penilaian oleh ahli media ditinjau dari aspek usability, functionality, dan komunikasi visual didapat rerata persentase kelayakan yaitu 88,75\% dengan kategori Sangat Layak. Hasil uji kelayakan oleh ahli materi ditinjau dari aspek desain pembelajaran, isi materi, bahasa dan komunikasi didapat rerata persentase kelayakan yaitu 85,00\% dengan kategori Sangat Layak, dan hasil penilaian oleh siswa berdasarkan aspek usability didapat rerata persentase kelayakan yaitu 79,33\% dengan kategori Sangat Layak.
\end{abstract}

Kata Kunci: Media, Pembelajaran, Dreamweaver, Web.

\begin{abstract}
This study aims to design web-based learning media to facilitate learning activities and present interactive material in order to increase students' interest in learning Natural Science subjects at SMAN 1 Kapoiala. The application used to design learning media is Dreamweaver and then a feasibility test is carried out by 2 media experts, 2 material experts and 20 students. The results of the feasibility test based on the assessment by media experts in terms of usability, functionality, and visual communication aspects obtained an average percentage of feasibility of $88.75 \%$ with the Very Appropriate category. The results of the feasibility test by material experts in terms of the aspects of learning design, material content, language and communication obtained an average percentage of eligibility, namely $85.00 \%$ in the Very Appropriate category, and the results of assessments by students based on the usability aspect obtained an average percentage of feasibility of $79.33 \%$. Very Eligible category.
\end{abstract}

Keywords: Media, Learning, Dreamweaver, Web.

\section{Pendahuluan}

Semakin meluasnya penggunaan teknologi komputer di era modern ini hampir digunakan diseluruh bidang kehidupan, khususnya dibidang pendidikan harus dapat mengikuti perkembangan teknologi terutama dalam bidang teknologi komputer. Menjadi suatu masalah apabila kegiatan pembelajaran tidak mengikuti perkembangan yang terbaik di era globalisasi seperti sekarang yang lebih mengedepankan penggunaan teknologi informasi, multimedia. Alat bantu teknologi yang berkaitan dengan komputer sangat dibutuhkan dalam proses pembelajaran yang lebih baik dan mudah. Misalnya saja alat pembelajaran untuk pembelajaran Ilmu Pengetahuan Alam. 
SMA Negeri 1 Kapoiala merupakan salah satu lembaga pendidikan yang ada di Sulawesi Tenggara tepatnya di Kabupaten Konawe. Dalam proses pembelajaran media yang digunakan masih bersifat konvensional dimana guru mengajar menggunakan buku, ebook, dan perangkat teknologi informasi seperti LCD (liquid crystal display), akan tetapi bahan ajar berupa handout disajikan dalam bentuk PPT (Power Point). Dari hasil observasi dilapangan didapat ada berbagai kekurangan dengan menggunakan media tersebut, diantaranya siswa hanya melihat, membaca, dan mendengar, tidak dapat berinteraksi dengan media pembelajaran secara langsung. Untuk itu, agar dalam proses pembelajaran terjadi interaksi antara siswa dengan bahan ajar maka dicoba membuat alternatif lain dengan membuat media pembelajaran berbasis web.

Dalam rangka menunjang kualitas pendidikan dalam penelitian ini akan dilakukan perancangan media pembelajaran yang dapat berinteraksi dengan bahan ajar dan dapat digunakan dengan mudah serta tidak terbatas dengan waktu yang dapat digunakan dimanapun dan kapanpun. Kemudahan media ini dapat digunakan secara offline maupun online. Dikatakan sebagai media pembelajaran karena media ini berisi tentang muatan pembelajaran diantaranya judul, tujuan, materi pembelajaran, dan evaluasi pembelajaran.

\section{Metode}

\subsection{Media}

Media adalah segala sesuatu yang dapat digunakan untuk menyalurkan pesan dari pengirim ke penerima sehingga dapat merangsang pikiran, perasaan, perhatian dan minat siswa sedemikian rupa sehingga terjadi proses belajar. Sedangkan pengertian lain secara sederhana media adalah alat yang menyampaikan atau mengantarkan pesan-pesan pembelajaran[1].

\subsection{Media Pembelajaran}

Media pembelajaran adalah seluruh alat dan bahan yang dapat dipakai untuk mencapai tujuan pendidikan. Menurut Arsyad media pembelajaran meliputi alat yang secara fisik digunakan untuk menyampaikan isi materi pengajaran, yang terdiri dari antara lain buku, tape recoder, kaset, video camera, foto, gambar, grafik, televisi dan komputer[1].

\subsection{Fungsi Media Pembelajaran}

Media pembelajaran dapat memenuhi tiga fungsi utama apabila media itu digunakan untuk perorangan, kelompok, atau kelompok pendengar yang besar jumlahnya, yaitu :

a. Memotivasi minat atau tindakan.

Untuk memenuhi fungsi motivasi, media pembelajaran dapat direalisasikan dengan teknik drama atau hiburan. Hasil yang diharapkan adalah melahirkan minat dan merangsang para siswa atau pendengar untuk bertindak (turut memikul tanggung jawab, melayani secara sukarela, atau memberikan sumbangan material). Pencapaian tujuan ini akan memperngaruhi sikap, nilai, dan emosi.

b. Menyajikan informasi

Untuk tujuan informasi, media pembelajaran dapat digunakan dalam rangka penyajian informasi dihadapan sekelompok siswa. Isi dan bentuk penyajian bersifat amat umum, berfungsi sebagai pengantar, ringkasan laporan, atau pengetahuan latar belakang. Penyajian dapat pula berbentuk hiburan, drama, atau teknik motivasi. Ketika mendengar atau menonton bahan informasi, para siswa bersifat pasif. Partisipasi yang diharapkan dari siswa hanya terbatas pada persetujuan atau ketidaksetujuan mereka secara mental, atau terbatas pada perasaan tidak/kurang senang, netral, atau senang. 
c. Memberi instruksi

Media berfungsi untuk tujuan instruksi dimana informasi yang terdapat dalam media itu harus melibatkan siswa baik dalam benak atau mental maupun dalam bentuk aktivitas yang nyata sehingga pembelajaran dapat terjadi. Materi harus dirancang secara lebih sistematis dan psikologis dilihat dari segi prinsip-prinsip belajar agar dapat menyiapkan instruksi yang efektif. Di samping menyenangkan, media pembelajaran harus dapat memberikan pengalaman yang menyenangkan dan memenuhi kebutuhan seorang siswa.

\subsection{Prosedur Pemilihan Media Pembelajaran}

Menurut Erickson menyarankan agar pemilihan media pembelajaran memperhatikan komponen-komponen berikut.

a. Instructional goals, yaitu tujuan pembelajaran yang dicapai. Untuk memilih media pembelajaran harus mengaitkan dengan kurikulum yang sekarang digunakan, berarti harus memperhitungkan standar kompetensi, kompetensi dasar, dan indikator.

b. Instructional content, yaitu materi pembelajaran. Untuk memilih media pembelajaran harus menyelaraskan dengan materi pembelajaran, baik tingkat kedalaman dan keluasan yang harus dicapai.

c. Learner characteristic, yaitu karakteristik siswa. Untuk memilih media pembelajaran harus mengaji sifat-sifat dan ciri media yang akan digunakan dengan dikaitkan dengan karakteristik siswa, baik secara kuantitatif (jumlah) ataupun kualitatif (kualitas, ciri, dan kebiasaan lain) dari siswa terhadap media yang akan digunakan.

d. Media selection, yaitu pemilihan media. Pemilihan media dapat dilakukan dengan cara membandingkan sejumlah media yang kemudian diputuskan.

\subsection{Media Pembelajaran Berbasis Web}

Media Pembelajaran Berbasis Web merupakan media pembelajaran yang di gunakan dalam proses pembelajaran dengan menggunakan software yang berbasis web yang berisi tentang muatan pembelajaran yang meliputi : judul, tujuan, materi pembelajaran, dan evaluasi pembelajaran. Hal tersebut sejalan dengan apa yang dikemukakan oleh Rober Heinich, dkk dalam [2] yang menyatakan bahwa Sistem komputer dapat menyampaikan pembelajaran secara invidual dan langsung kepada para siswa/peserta didik dengan cara berinteraksi dengan mata pelajaran yang diprogramkan kedalam sistem komputer, inilah yang disebut dengan pembelajaran berbasis web.

\subsection{Dreamweaver}

Macromedia Dreamweaver merupakan sebuah software yang menangani tata letak (layout) halaman web. Macromedia Dreamweaver adalah program aplikasi professional untuk merubah HTML secara visual dan mengelola Website serta pages. Karena tampil secara visual, aplikasi Macromedia Dreamweaver 8 mudah di operasikan. Program ini menyediakan banyak perangkat yang dapat meningkatkan kemampuan user didalam membuat web [3].

\subsection{Kerangka Konseptual}

Berikut gambaran tentang alur prosedur dalam perancangan media pembelajaran berbasis web pada mata pelajaran IPA di SMA Negeri 1 Kapoiala agar dapat di implementasikan dengan baik. 


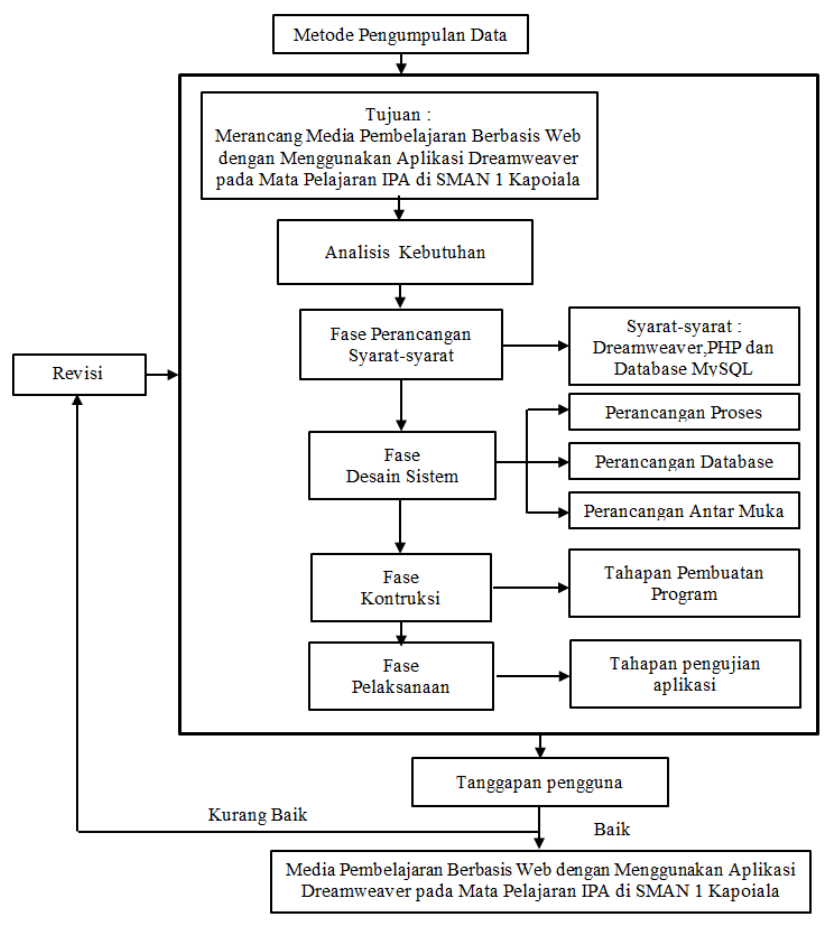

Gambar 2.1 Tahapan Perancangan Media Pembelajaran

\subsection{Prosedur Rancangan Program}

Prosedur rancangan media pembelajaran berbasis web dengan menggunakan aplikasi dreamweaver di SMAN 1 Kapoiala yang digunakan pada penelitian ini dapat dilihat pada gambar 2.2.

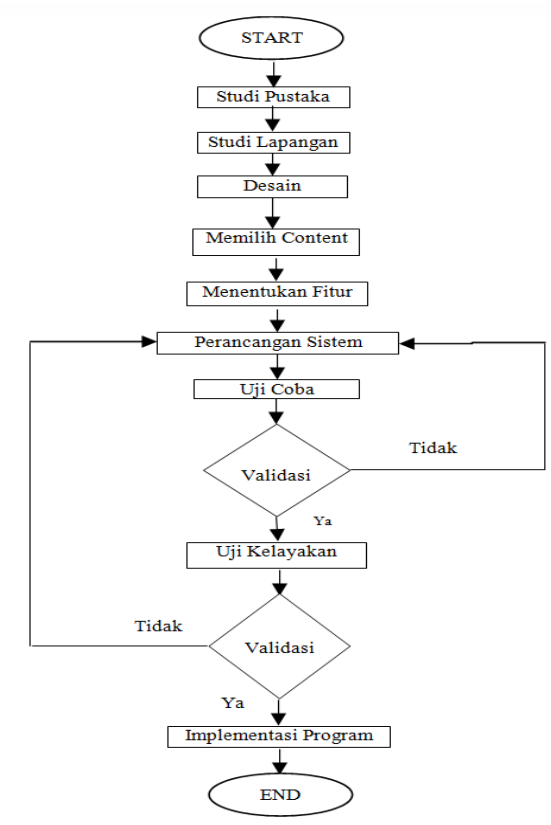

Gambar 2.2. Flowchart Rancangan Program 


\section{Hasil dan Pembahasan}

\subsection{Implementasi Program}

Implementasi program merupakan tahap menterjemahkan desain ke tampilan sebenarnya dalam bentuk media pembelajaran berbasis web. Implementasi program media pembelajaran berbasis web pada mata pelajaran IPA di SMA Negeri 1 Kapoiala adalah sebagai berikut:

a. Halaman Home

Pada tampilan depan aplikasi memuat :

1. Bagian atas adalah Header yaitu terdapat nama sekolah dan alamat sekolah.

2. Bagian window terdapat menu yang terdiri dari : Home, About, Materi-Materi, Video Tutorial, Evaluasi, dan Referensi serta terdapat ucapan selamat datang dan identitas mata pelajaran serta identitas sekolah.

3. Bagian bawah terdapat footer yang bertuliskan Copyright (C) 2020 SMA Negeri 1 Kapoiala.

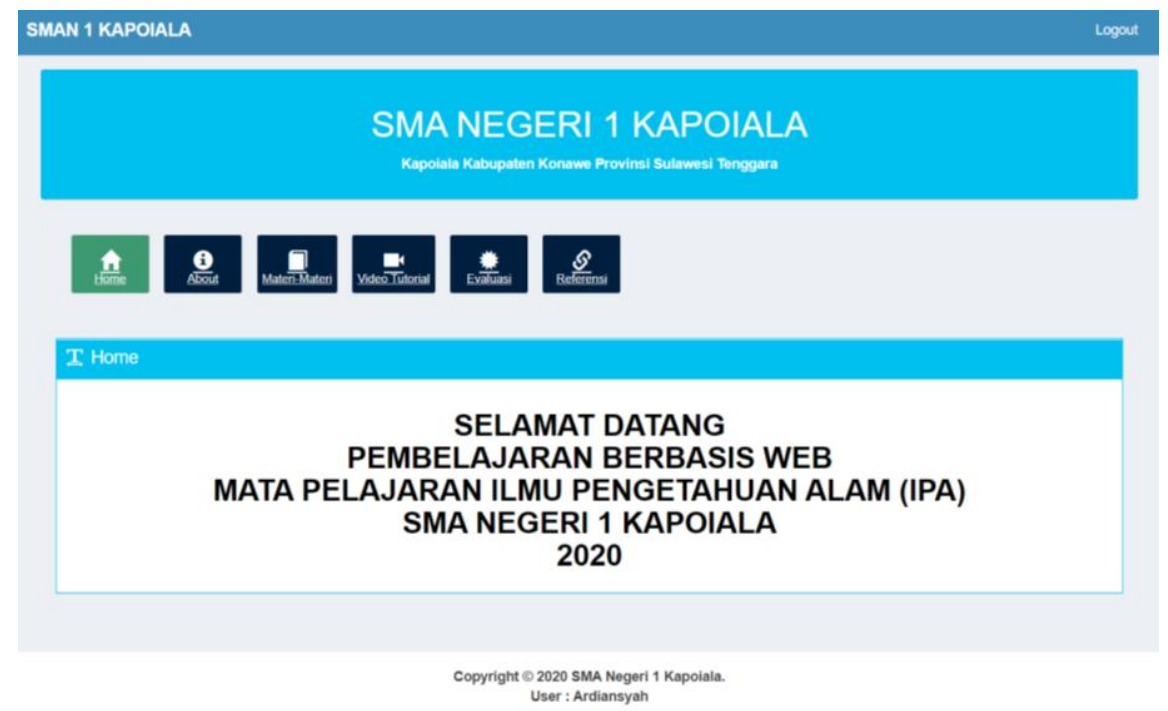

Gambar 3.1. Implementasi Tampilan Home

Penjelasan struktur menu :

1. Home berisi ucapan selamat datang, identitas mata pelajaran dan identitas sekolah.

2. About berisi informasi tentang aplikasi media pembelajaran.

3. Materi-Materi berisi tentang kumpulan materi yang menjadi bahan pembelajaran. Di setiap materi di lengkapi dengan indeks setiap pertemuan untuk memudahkan berpindah kehalaman lain.

4. Video Tutorial berisi tentang kumpulan materi berbentuk video yang menjadi bahan pembelajaran.

5. Evaluasi memuat soal-soal pilihan ganda dari materi yang disajikan pada menu materi. Soal dapat di kerjakan secara langsung dan dilihat hasilnya setelah soal selesai di kerjakan.

6. Referensi berisi referensi yang digunakan dalam pengajaran mata pelajaran Ilmu Pengetahuan Alam (IPA). 
Jurnal Sistem Informasi dan Sistem Komputer, Vol. 5, No. 2, Juli 2020 pISSN: 2581-1614 eISSN: 2715-906X

b. Halaman Menu About

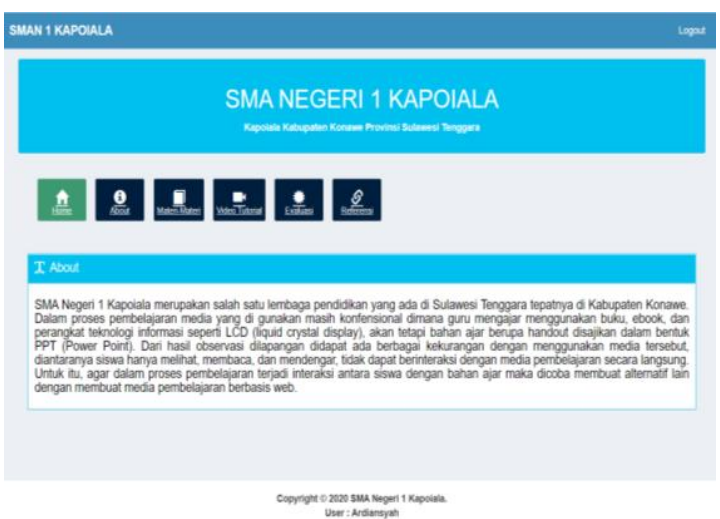

Gambar 3.2 Halaman Menu About

c. Halaman Menu Materi

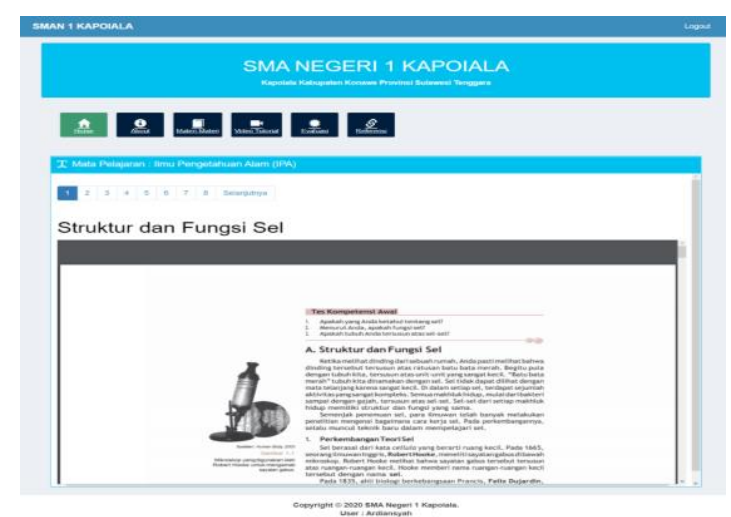

Gambar 3.3 Halaman Menu Materi

d. Halaman Menu Video Tutorial

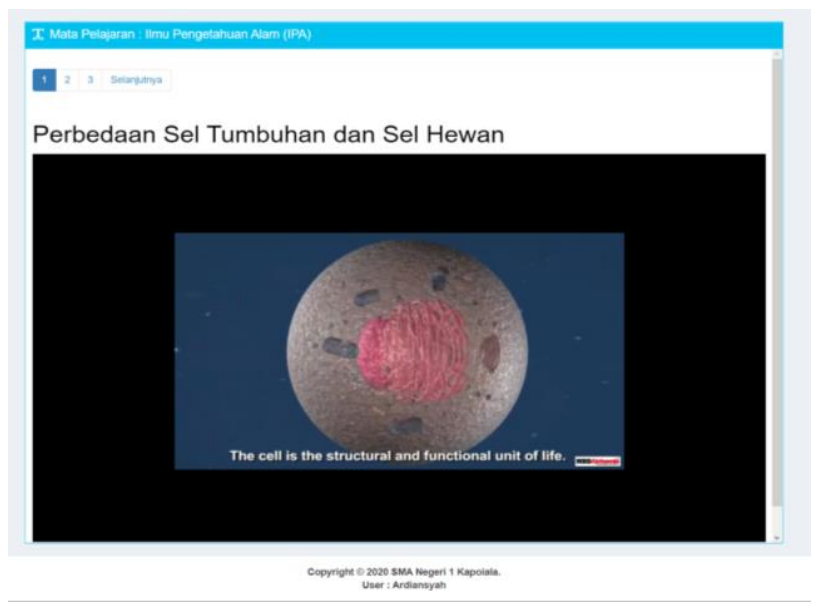

Gambar 3.4 Halaman Menu Video Tutorial 
Jurnal Sistem Informasi dan Sistem Komputer, Vol. 5, No. 2, Juli 2020

pISSN: 2581-1614 eISSN: 2715-906X

e. Halaman Menu Evaluasi

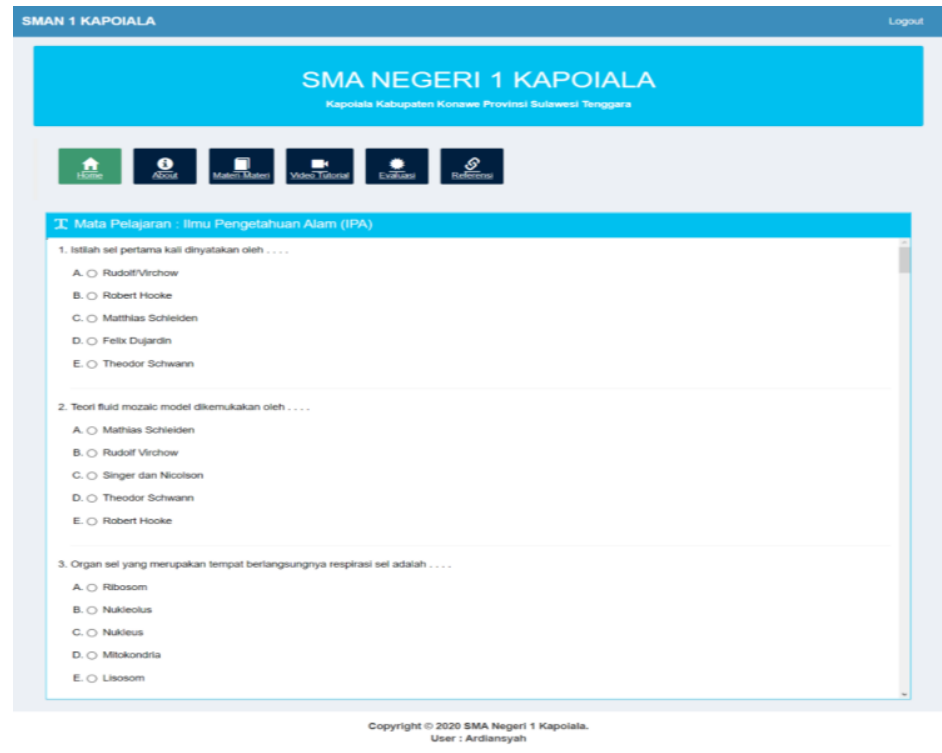

Gambar 3.5 Halaman Menu Evaluasi

f. Halaman Hasil Evaluasi

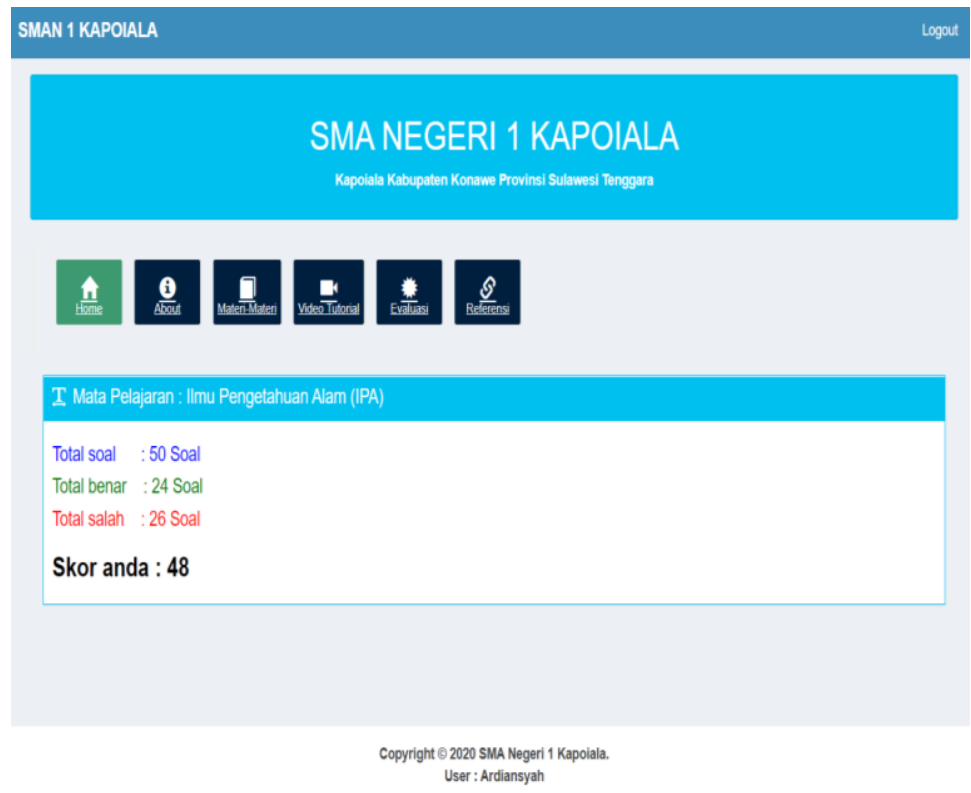

Gambar 3.6 Halaman Hasil Evaluasi 
Jurnal Sistem Informasi dan Sistem Komputer, Vol. 5, No. 2, Juli 2020 pISSN: 2581-1614 eISSN: 2715-906X

\subsection{Uji Coba Media Pembelajaran}

Data uji coba media pembelajaran diperoleh dari validasi ahli media, validasi ahli materi dan uji coba pada siswa dengan mengisi instrumen berupa kuisioner pengujian kelayakan media pembelajaran. Berdasarkan hasil analisis data pengujian maka dapat ditampilkan grafik data hasil pengujian yang dapat dilihat seperti berikut:

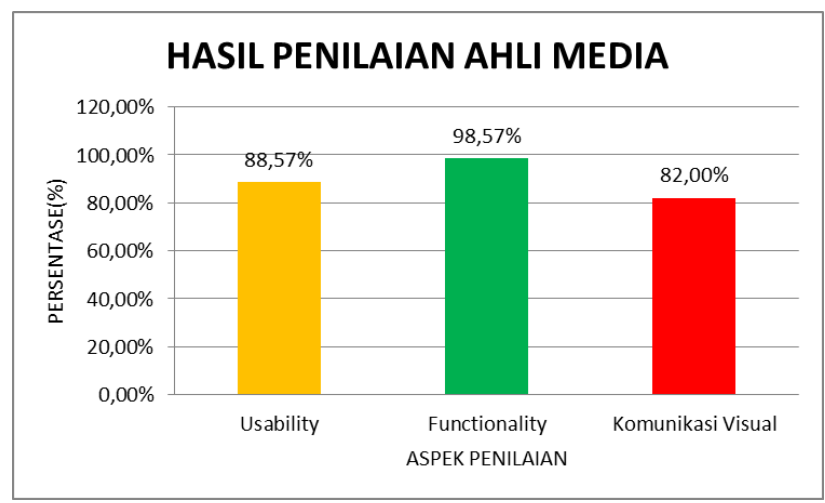

Gambar 3.7. Hasil Penilaian Ahli Media

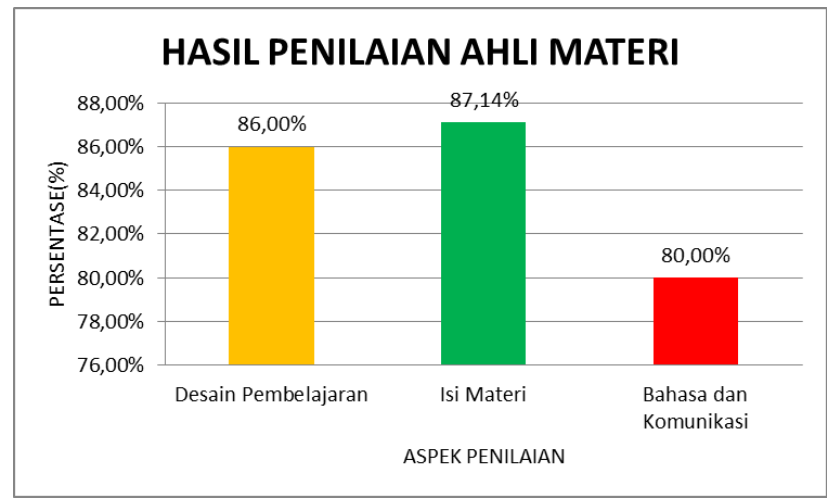

Gambar 3.8. Hasil Penilaian Ahli Materi

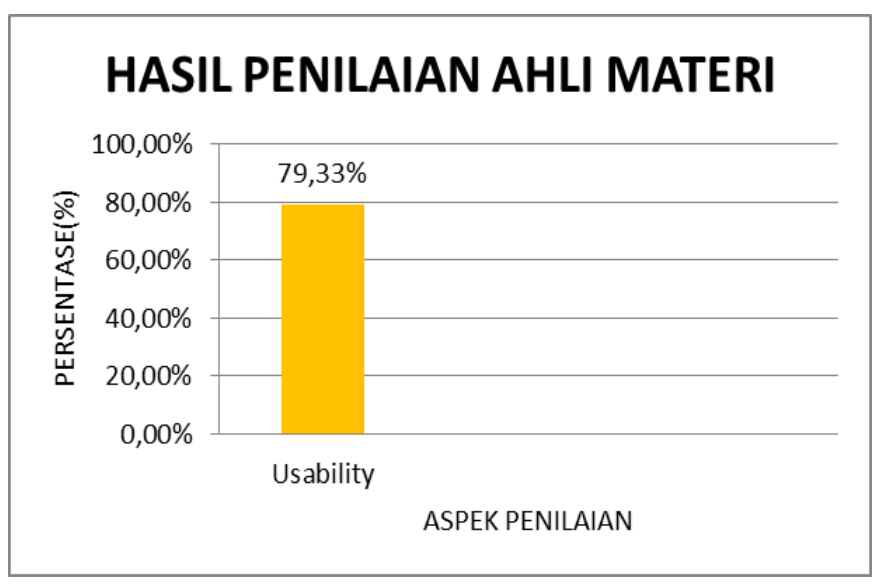

Gambar 3.9. Hasil Pengujian Siswa 


\subsection{Pembahasan}

Media pembelajaran berbasis web yang telah dibuat yang selanjutnya dilakukan uji coba oleh ahli media dan ahli materi untuk mengetahui kelayakan media tersebut. Media pembelajaran yang telah di validasi oleh ahli media dan ahli materi di uji coba kepada siswa dalam bentuk kuisioner.

Berdasarkan hasil penilaian media pembelajaran oleh ahli media dengan melibatkan 2 orang ahli media didapat skor persentase kelayakan dari aspek usability 88,57\%, aspek functionality $98,57 \%$, dan aspek komunikasi visual $82,00 \%$, sehingga didapat rerata persentase kelayakan yaitu $88,75 \%$ dan media pembelajaran berbasis web dapat dikategorikan "Sangat Layak".

Berdasarkan hasil penilaian media pembelajaran oleh ahli materi dengan melibatkan 2 orang ahli materi didapat skor persentasi kelayakan dengan menunjukkan aspek desain pembelajaran mendapatkan persentase sebesar $86,00 \%$, aspek isi materi mendapatkan skor sebesar $87,14 \%$, dan aspek bahasa dan komunikasi mendapatkan skor $80,00 \%$. Hasil rerata dari ketiga aspek tersebut didapat persentase sebesar $85,00 \%$ dan media pembelajaran berbasis web dapat dikategorikan "Sangat Layak".

Penilaian media pembelajaran oleh siswa dilakukan setelah mendapatkan validasi oleh ahli media dan ahli materi. Hasil penilaian dari siswa terhadap media pembelajaran berbasis web berdasarkan aspek usability dengan 15 pertanyaan diperoleh skor 1190 dari 1500 dengan persentase 79,33\% dan media pembelajaran berbasis web dapat dikategorikan "Sangat Layak". Sehingga disimpulkan bahwa media pembelajaran berbasis web pada mata pelajaran Ilmu Pengetahuan Alam (IPA) layak dan dapat digunakan sebagai media pembelajaran di SMA Negeri 1 Kapoiala.

\section{Kesimpulan dan Saran \\ 4.1 Kesimpulan}

Media pembelajaran berbasis web pada mata pelajaran Ilmu Pengetahuan Alam (IPA) di SMA Negeri 1 Kapoiala yang dirancang sangat layak digunakan untuk mendukung media pembelajaran mata pelajaran IPA di SMA Negeri 1 Kapoiala. Media pembelajaran yang di rancang ini dapat digunakan sebagai media pembelajaran untuk beberapa mata pelajaran yang ada di SMA Negeri 1 Kapoiala.

\subsection{Saran}

Dari kesimpulan yang telah di uraikan maka dapat di berikan saran sebagai berikut:

1. Diharapkan dalam proses pengembangan selanjutnya aplikasi media pembelajaran ini dilengkapi dengan berbagai fitur sesuai dengan kebutuhan.

2. Pada penelitian selanjutnya disarankan agar melihat pengaruh media pembelajaran berbasis web terhadap prestasi siswa.

3. Diharapkan agar sekolah yang menggunakan aplikasi media pembelajaran berbasis web dapat menyediakan sarana dan prasarana untuk mensosialisasikan kepada para guru dan siswa/i yang akan menggunakan aplikasi media pembelajaran berbasis web.

\section{Daftar Pustaka}

[1] Arsyad, Azhar,“Media Pembelajaran”, Jakarta: PT. Raja Grafindo Persada, 2013.

[2] Rusman, Belajar dan Pembelajaran Berbasis Komputer Mengembangkan Profesionalisme Guru Abad 21, Bandung: Alfabeta, 2012. 
Jurnal Sistem Informasi dan Sistem Komputer, Vol. 5, No. 2, Juli 2020

pISSN: 2581-1614 eISSN: 2715-906X

[3] Bunapit, Ahmad, Cara Mudah Belajar Internet Home Site dan HTML, Jakarta: Penerbit Dinastindo, 2008.

[4] Rusman, Model-Model Pembelajaran Mengembangkan Profesionalisme Guru, Jakarta: CV. Rajawali, .

[5] Hidayatullah, Priyanto, Pemrograman Web, Bandung: Informatika Bandung, 2014.

[6] Sugiono, Metode Penelitian Kuantitatif, Kualitatif dan R\&D, Bandung: Alfabeta, 2010. 